\title{
The Effects of Gavage Extract of Papaver Rhoeas $L$ on Blood Pressure of MIA Induced Osteoarthritis and Its Interaction with Nitrergic System in male Rat
}

\author{
Sareh Sangy ${ }^{1}$, Faeghe Miryousefiata ${ }^{2}$, Aminollah Bahaoddini $^{3}$, Herlina Dimiati ${ }^{4}$ \\ ${ }^{1}$ Department of Biology, Faculty of Science, Shiraz University, Shiraz, Iran \\ ${ }^{2}$ Medical Student, Osmangazi University, Eskisehir, Turkey \\ ${ }^{3}$ General Practitioner, School of Medical Science, Tehran Branch, Islamic Azad University, Tehran, Iran. \\ Shiraz. Iran \\ ${ }^{4}$ Pediatric Cardiology Division, Department of Child Health, Medical School, Universitas Syiah Kua la, \\ Zainoel Abidin Hospital, Banda Aceh, Indonesia \\ sareh.sangy@gmail.com,herlinadimiati@unsyiah.ac.id
}

\begin{abstract}
Hypertension is one of the most common and most prevalent diseases in the world today. Chronic inflammation is one of the risk factors for cardiovascular disease (CVD). Since synovial inflammation plays a role in the initial stages of osteoarthritis (OA), therefore, the side effects of $O A$ are the incidence of CVD. One of the most appropriate methods for treating this disease is the use of medicinal herbs that have a blood pressure modifying effect Due to OA as Papaver rhoeas. The present research shows The Effects of Extract of Papaver rhoeas on Blood Pressure of rats with OA and Its Interaction with nitrergic System. OA model in 35 male rats was created by injection of monosodium iodoacetate (MIA) into the right knee joint and then were gavaged with extract of Papaver rhoeas for 30 days. On day 30, the veins and arteries of the animal were then cannulated for injection and measurement of blood pressure, respectively. Blood pressure parameters (systolic, diastolic, mean arterial pressure) were recorded in groups before and after L-NAME injection. The results were analyzed using SPSS software. Systolic, diastolic, and mean arterial pressure in response to extract of Papaver rhoeas was reduced compared to control(OA), as well as Significant decrease in systolic and diastolic pressure and mean arterial pressure and increased heart beat rate in the presence of extract and LNAME as compared with control group. ( $P<0 / 05)$. We found that the aqueous extract of Papaver rhoeas has a decreasing effect on blood pressure in rats with OA. This effect may be due to inhibition of the nitrergic system.
\end{abstract}

Keywords: papaver rhoeas; nitrergi; blood pressure; osteoarthritis; rats

\section{Introduction}

Hypertension is one of the most common and prevalent diseases in the world today. It often grows without being noticed and it may end up with cardiovascular diseases or severe heart failure. Therefore, hypertension should be controlled and treated carefully (1).

Cardiovascular diseases (CVD) are one of the major reasons of death in the whole world. It covers more than one third of death causes in western countries and 50 percent of death causes in Iran which is also the major cause of death. Studies have shown that systematic and chronic inflammation can increase getting cardiovascular disease.

Osteoarthritis (OA) is also a common degenerative disorder in articular cartilage along with hypertrophic changes in subchondral bone which causes the surrounding tissues to inflame. The knee osteoarthritis is the most common type and is considered to be the most important cause of disability in elderly people. The most common sign of osteoarthritis is the joint pain. Since synovial inflammation plays a role in the initial stages of osteoarthritis (OA), therefore, the side effects of OA are the incidence of CVD (9). In addition, the first stage in OA medication is the use of anti-inflammatory non-steroid (NSAID) drugs which has 
dangerous side effects in causing CVD (10). Therefore, it could be helpful to apply other treatment methods such as use of herbal drugs that have rectifying effect on hypertension (1). Papaver rhoeas L. is from Papaveraceae plants which contains various types of alkaloids and is from the family of Poppy and has similar effects (2). And because of having very little amount of morphine in its extract, it is called harmless opium (3) and many of its good characteristics have been reported. The existing active ingredients in Papaver rhoeas $\mathrm{L}$. include: Papaverine, anthocyanin, radin, radic acid, papauric acid and roagenin. Papaverine is one of the opium alkaloids which is used to cure vascular congestion specially in the heart vessels. Papaverine decreases the Potassium-Sodium pump activity. In addition, it restrains phosphodiesterase enzyme. Also, the studies of Marco and colleagues show that the other advantage of the restraining of phosphodiesterase is its diastolic operation on left ventricle.

Another main alkaloids of Papaver rhoeas L. is anthocyanin which is known for its antithrombotic effects, endothelium expansion, improvement of arterial stiffness, protective effect on heart by defeating the increasing hyper trophy-phosphorylation in protein kinas $\mathrm{C}$, and activation of Akt in protein kinas B (5) \& (6).

Nitric Oxide is a gaseous molecule with physiological and pathological operation and has a major rule in cardiovascular system adjustment via central and surrounding effects. In consideration with the environmental effects, nitric oxide is mainly synthesized in endothelium and causes vascular relaxation with increasing guanosine mono phosphate. Previous studies show that hypertension occurs when nitric oxide production in artery is restricted (7). Antagonist, nitric oxide synthetize enzyme is L-NAME or (L-NGnitroarginine methylester).

Harmful side effects of chemical drugs in the end of twentieth century caused the scientists to turn to herbal drugs. Therefore, using alternative methods, such as herbal drugs, can prevent the side effects to occur; and since the papaver rhoeas L. has a wide treatment effects on curing the vascular congestion and considering that gavage extract of papaver rhoeas had no signs of side effects. Therefore, in the present report, we have tried to study the effect of papaver rhoeas extract on hypertension and interference effect of nitrergic.

Goats are small ruminant animals that function as meat and milk-producing. Goat is livestock biologically productive, easily adaptable to tropical and sub-tropical environments, relatively easy maintenance. Indonesia has a very diverse source of genetic goats both imported and local goats with high productivity. (Azis , 2020)

The change of shear stress versus strain rate inside a fluid which depends on viscosity can be classified as a linear, nonlinear or plastic response. When the shear stress is linearly proportional to the strain rate it is known as Newtonian fluid, the constant of proportionality being the coefficient of dynamic viscosity.( Zigta,36)

\section{Materials and Method}

Maceration method has been used to prepare the papaver rhoeas extract. The plants in surrounding cities of Shiraz were collected and were identified and confirmed by the Botany professor of the Science College of Shiraz University. Then, the collected plants were dried and powdered by electric blender and was put in a 1800 milliliter jar containing $70 \%$ ethanol for 72 hours. Then it was passed through a filter and poured over the powder and remained for another 72 hours in incubator with 37 degrees Celsius until it became completely dry and turned into powder. 


\subsection{Grouping}

35 immature male rats that were thirty days old were tested in following groups:

Control group - gavage $70 \%$ ethanol in rat suffering Osteoarthritis) - testing group papaver rhoeas extract with doses of 100, 200, and $400 \mathrm{mg} / \mathrm{kg}$ in rats suffering Osteoarthritis that variables of arterial blood pressure, systolic pressure, and diastolic pressure were measured in $\mathrm{mm} \mathrm{Hg}$ at the day of surgery.

\subsection{Testing Methodology}

35 mature male rats from wistar race that were thirty days old and had weights from 100 to 150 grams were kept in eliminated conditioned room for one week (12 hours with having light and 12 hours with no light) and temperature of 22+- 3 degrees Celsius and having sufficient amount of food and water.

\subsection{Preparation of Osteoarthritis Model}

At first, the animal was injected via urethane (with dose of $0.5 \mathrm{~g} / \mathrm{kg}$ ) and became unconscious and then its right knee was sterilized with $100 \%$ ethanol and using a G 27 sterile needle, $1 \mathrm{mg}$ monosodium iodostat (MIA 'MIA; sigma-ALDRICH, USA) with $50 \mu \mathrm{L}$ was injected in its longitudinal groove in knee joint which was in its maximum flexion. Of course, these were done while no harm was done to subchondral bone; and then Osteoarthritis was prepared (11\& 12) see Figure 1 .
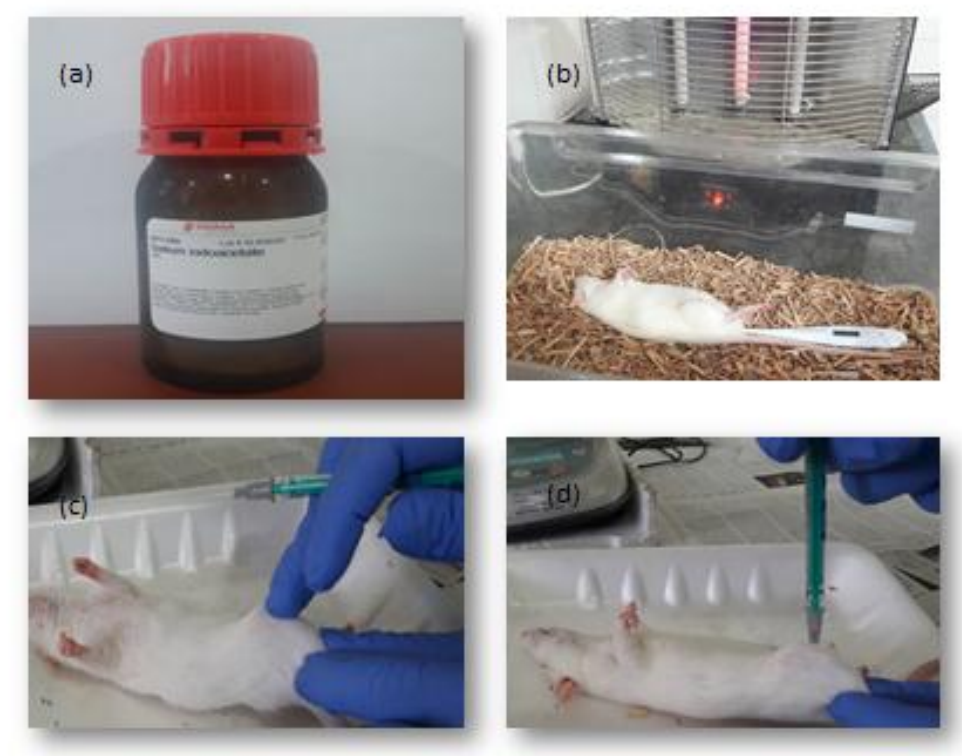

Figure No.1 Intra-articular injection method (MIA) into rat's knee; a) view of vial monosodium iodostat (MIA); b) making animal unconscious by injecting urethane (dose of $0.5 \mathrm{~g} / \mathrm{kg}$ ); c) selection of appropriate place and sterilizing knee joint with $100 \%$ ethanol; d) Induction of cartilage defects by injecting $1 \mathrm{mg}$ monosodium iodostat in the longitudinal groove in right knee joint of the rat. 


\subsection{Protocol on How to Prescribe Drugs}

One week after preparation of Osteoarthritis model, gavage of the papavera rhoeas extract was done daily for 14 days in different dosages (dose of $100 \mathrm{mg} / \mathrm{kg}$ equivalent to 0.23 $\mathrm{gr} / \mathrm{kg}$ extract powder), (dose of $200 \mathrm{mg} / \mathrm{kg}$ equivalent to $0.46 \mathrm{~g} / \mathrm{kg}$ extract powder), (dose of $400 \mathrm{mg} / \mathrm{kg}$ equivalent to $0.1 \mathrm{~g} / \mathrm{kg}$ extract powder) in 300 micro litter solvent (water and alcohol). After two weeks of gavage, in day 30, the animals which were restricted from food 12 hours before the start of the test but had full access to water, became unconscious by Intraperitoneal injection of urethane (Sigma-Aldrich, St. Louis, MO, USA) with dose of 0.5 $\mathrm{g} / \mathrm{kg}$ and Tracheostomy was done to prevent aspiration and suffocation during unconsciousness. Then, vein and artery of the animal were channeled by canal hairier for injection of drug and measuring blood pressure. Artery canal was connected to pressure transducer of power lab device (AD Instruments, Sydney, Australia) for recording the pressure. The power lab device was connected to a computer equipped with Lab Chart 7 software (AD Instruments, Sydney, Australia) which by using that in all groups, the blood pressure of animals was recorded for 20 minutes and then LNAME (which was provided from Merk company in Germany) was injected via artery canal and then the pressure was recorded. At the end of surgery, the animal was rested for one hour in order to clear the side effects of the tension in surgery and make it stabilize; and then the blood pressure was recorded.

\subsection{Statistical Analysis of Data}

The recorded graphs were converted into numbers by using Lab Chart software, and these numbers were confirmed by SPSS 19 version and by using the Paired-Samples T Test. Then, the One-Way ANOVA test was used to compare the groups and also the data was analyzed by considering the meaningful level $(\mathrm{P}<0.05)$. The LSD test was used to compare the averages of the data. The data are shown as mean standard deviation.

\subsection{Findings}

Among the different doses that were tested, decrease in mean artery pressure for oral extract with dose of $200 \mathrm{mg} / \mathrm{kg}$ was recorded. As it can be seen in Figure No. 2, the mean artery pressure, systolic pressure for dose 200 has a meaningful difference with control group (affected to OA), and the average parameters of diastolic and systolic pressure in control group is the highest and the average parameters of artery mean pressure, diastolic and systolic pressure in group with dose of 200 is the lowest; also, as it is seen in Graph No. 3, the average heart beat in control group is the lowest.

\begin{tabular}{|c|c|c|c|c|}
\hline $\begin{array}{c}\text { Group } \\
\mathrm{N}=5\end{array}$ & Heart Beat & Artery Mean Pressure & Systolic Pressure & Diastolic Pressure \\
\hline Control & $296.30 \pm 25.81$ & $107.78 \pm 5.75$ & $126.09 \pm 4.76$ & $98.63 \pm 3.88$ \\
\hline $\begin{array}{c}\text { Affected to } \\
\text { OA }\end{array}$ & $364.39 \pm 12.41$ & $128.91 \pm 5.46$ & $164.99 \pm 5.55^{\circ}$ & $110.87 \pm 4.88$ \\
\hline $\begin{array}{c}\text { Dose of } \\
200\end{array}$ & $316.97 \pm 27.21$ & $101.31 \pm 7.36^{\mathrm{b}}$ & $114.95 \pm 5.44^{\mathrm{b}}$ & $85.87 \pm 3.88$ \\
\hline
\end{tabular}

Figure No. 2. Comparison between systolic and diastolic blood pressure with artery mean pressure for control groups affected to OA and receiving dose of 200 papavera rhoeas extract as oral

a) Shows the meaningful difference between control group (affected to OA) and cotrol

b) Shows the meaningful difference between group with dose of 200 and solvent group with $\mathrm{P}<0.05$ 


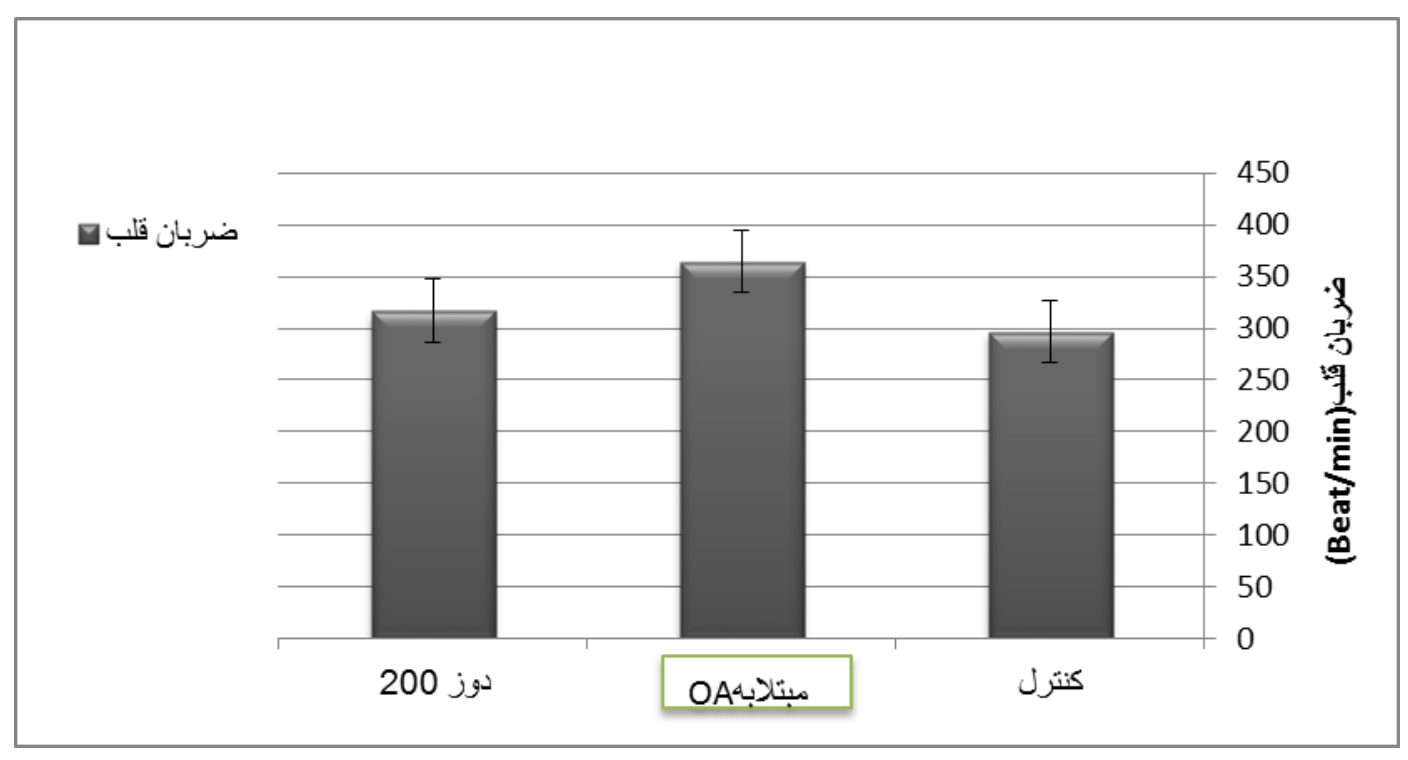

Graph No. 3. Heart Beat in Control Groups, Affected to OA and Receivers of Dose 200 of Papavera Rhoeas Extract as Oral

As it is shown in Table 1 below, the systolic, diastolic, and mean artery pressures is reduced in control LNAME and LNAME with oral extract as it is compared to the control group, and its value in LNAME with extract is greater than the one in control LNAME (as seen in Figure No. 4). But the heart beat in oral extract LNAME has increased as compared to the control group, and the amount of increase is much more in LNAME with extract (as seen in Graph No. 5).

Table No. 1. Variations in systolic, diastolic, and artery mean pressure (in $\mathrm{mm} \mathrm{Hg}$ ) and heart beat (in beat/min) in response to LNAME and LNAME with oral extract

a) Shpws the meaningful difference between LNAME group and control grouph with $\mathrm{P}<0.05$

b) Shows the meaningful difference between LNAME group and control group with $\mathrm{P}<005$

\begin{tabular}{|c|c|c|c|c|}
\hline Iroup & Heart Beat & $\begin{array}{c}\text { Artery Mean } \\
\text { Pressure }\end{array}$ & $\begin{array}{c}\text { Systolic } \\
\text { Pressure }\end{array}$ & $\begin{array}{c}\text { Diastolic } \\
\text { Pressure }\end{array}$ \\
\hline Control & $296.30 \pm 25.81$ & $107.78 \pm 5.75$ & $126.09 \pm 4.76$ & $98.63 \pm 3.88$ \\
\hline LNAME & $372.29 \pm 7.24^{\star 凶}$ & $72.33 \pm 2.91^{\star े}$ & $91.64 \pm 2.80^{3}$ & $62.67 \pm 3.19^{\circ}$ \\
\hline $\begin{array}{c}\text { LNAME with } \\
\text { extract }\end{array}$ & $374.77 \pm 11.11^{\circ}$ & $70.00 \pm 2.71^{\mathrm{b}}$ & $88.96 \pm 2.82^{\mathrm{b}}$ & $60.53 \pm 2.90^{\mathrm{b}}$ \\
\hline
\end{tabular}




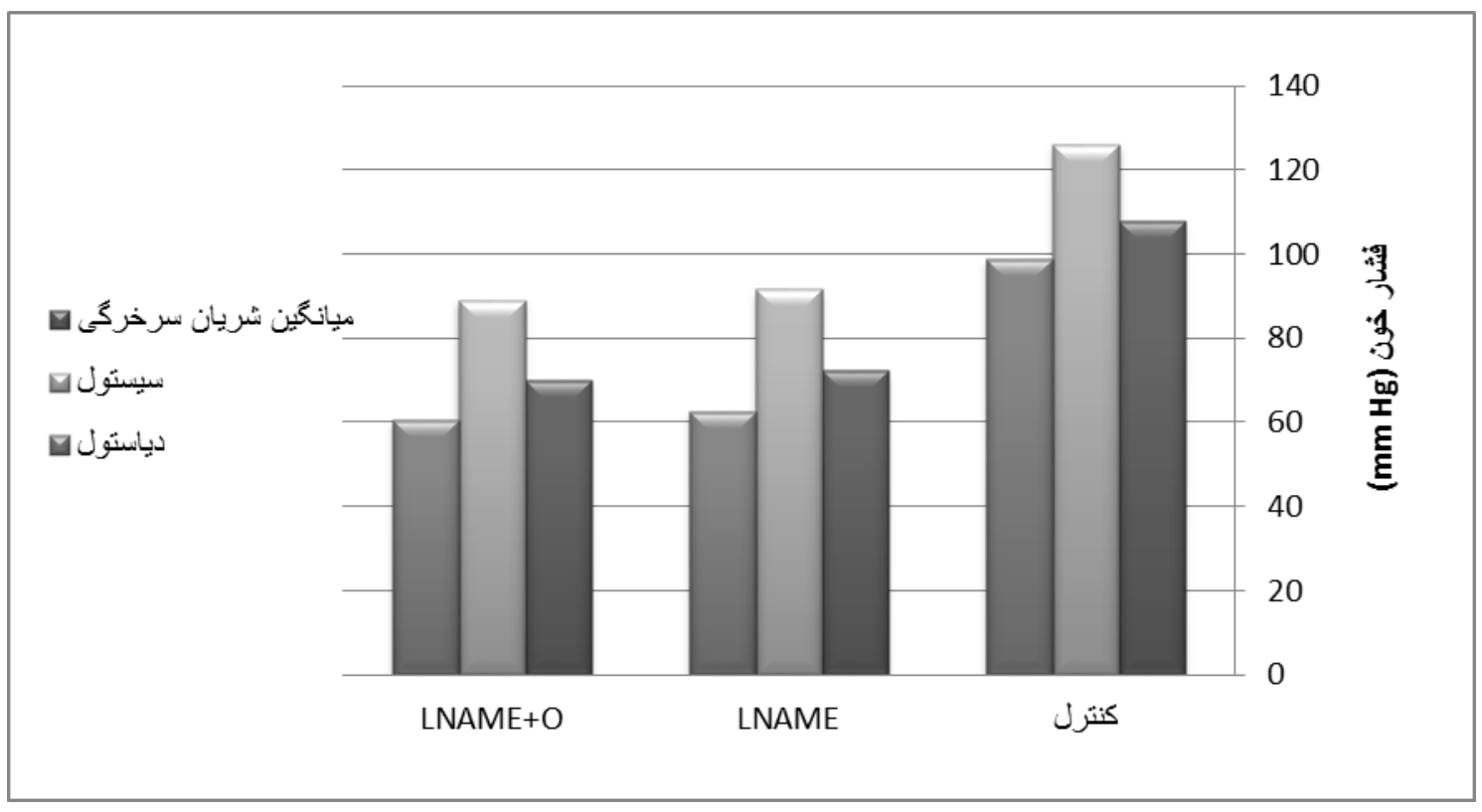

Graph No. 4. Comparison between systolic, diastolic, and artery mean blood pressure for control groups, LNAME receivers, and LNAME with oral extract receivers:

a) Shows the meaningful difference between LNAME group and control group with $\mathrm{P}<0$.

b) Shows the meaningful difference between LNAME with extract group and control group with $\mathrm{P}<0.05$.

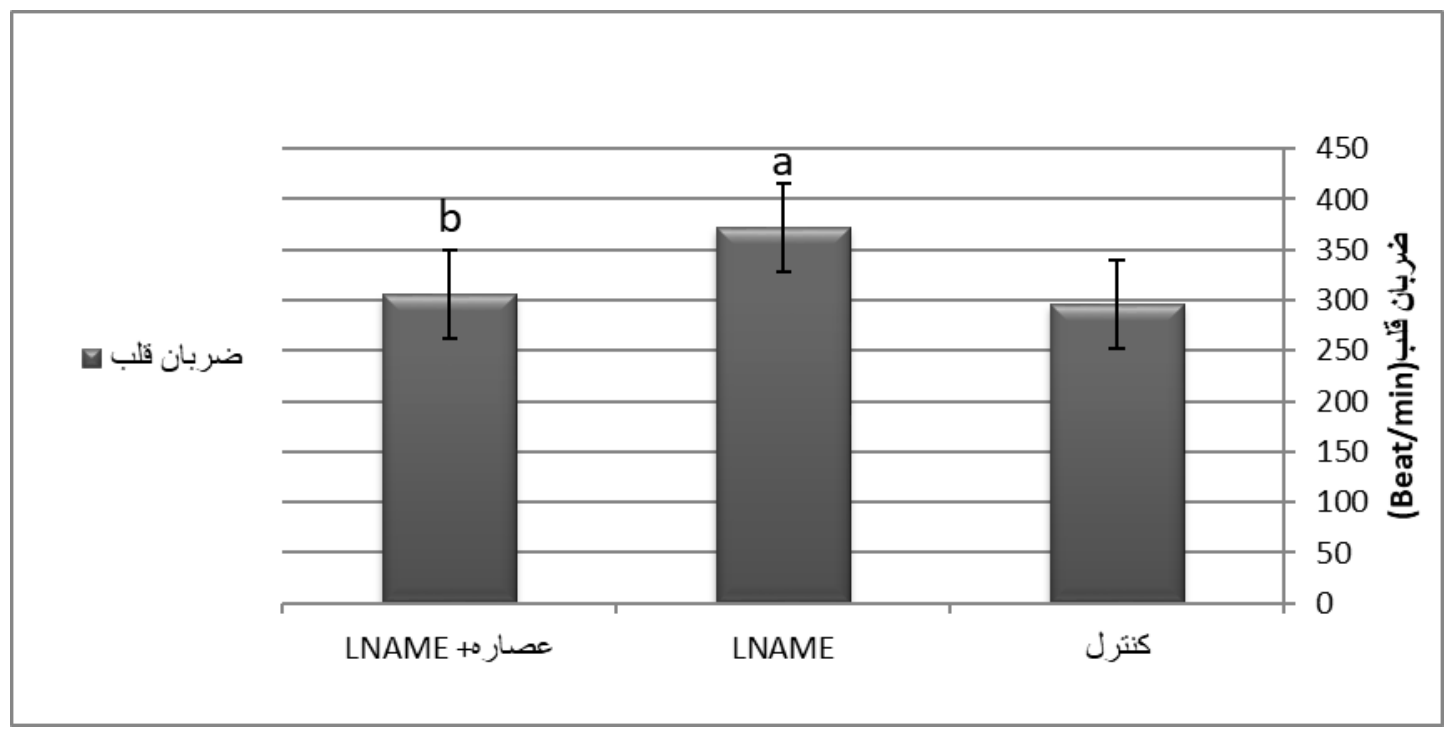

Graph No. 5. Comparison of Heart Beats between Control Groups, LNAME Receivers, and LNAME with Oral Extract Receivers

\section{Discussion and Conclusion}

The results obtained from this research shows that diastole, artery mean pressure, and heart beat in rats affected with Osteoarthritis is increased as compared to control groups. In line with the results obtained in this paper, Huston and his colleagues (2015) showed a linear relation between Osteoarthritis severity and cardiovascular disease. Also, Wang and his colleagues (2016) expressed in meta-analysis that there are strong evidences which shows that $\mathrm{OA}$ is an important danger factor for $\operatorname{CVD}(16,17$, and 18). 
On the other hand, as it was shown in present research, papaver rhoreas oral extract with dose of $200 \mathrm{mg} / \mathrm{kg}$ causes the mean artery pressure, systolic and diastolic pressures to reduce and heartbeat to increase as compared to healthy rats; and decreases as compared to rats affected to arthrosis which can be because of the effect of oral extract on cardiac output or change in vascular resistance. And since papaver rhoeas oral extract decreases systolic pressure as compared to control state, then it can be concluded that causes the decrease in cardiac output. It has also been shown in results that papaver rhoeas oral extract causes increase in heartbeat; therefore, it can be said that the decrease of cardiac output from papaver rhoeas oral extract is obtained via decrease in impact volume and finally decrease in contractile power of heart. This effect can be arising from existence of papaverine and various active ingredients in extract. The results of previous researches show that the existing papaverine in papaver rhoeas decreases the pumpage activity of sodium-potasium. In addition, it causes Phosphodiesterase enzyme to be restrained. The studies of Marco and his colleagues also show that the other advantage of Phosphodiesterase enzyme entrainment is its diastolic operation on left ventricle which is aligns with the study of the present paper $(14 \&$ $15)$.

In extract group, for analyzing possible mechanism involved in low blood pressure because of extract, LNAME was used (a NOS inhibitor) as nitrergic system emulator. As it was mentioned in results section, co-injection of papaver rhoeas L. oral extract with dose of $200 \mathrm{mg} / \mathrm{kg}$ and LNAME causes decrease in systole pressure and artery mean pressure and increase in heartbeat as compared to its control group (injection of LNAME). In another word, premedication with papaver rhoeas water alcohol extract was able to reduce the hypertension caused by LNAME injection; this is because NO has normalizing effect on sympathetic nervous system (8). Therefore, we can conclude that papaver rhoeas water alcohol extract has possibly anti nitrergic properties. The findings of present paper with researches done by Farokhy and his colleagues (2017) and Redi and his colleagues (2007) are consistence ( 7 \&13). Also, inhibition of this system can be obtained through different receivers. But, in order to answer to this question that whether this inhibition is occurred at the level of cardiovascular receivers or it has had a central effect, more research would be necessary.

\section{Acknowledgment}

Financial support received from Biology Department of the Shiraz University for fulfillment of our research is greatly appreciated; we also appreciate the ethics committee of the Biology Department which this paper was performed under their supervision and following all ethics.

\section{Funding}

The authors gratefully acknowledge the Islamic Azad University of Kerman for financial supports.

\section{References}

Agnieszka Pajak, Magdalena Kostrzewa, Natalia Malek, Michal Korostynski, Katarzyna Starowicz.(2017). Expression of matrix metalloproteinases and components of the endocannabinoid system in the knee joint are associated with biphasic pain progression in a rat model of osteoarthritis $J$ Pain Res.

Azis1. R , Ciptadi.G, Suyadi.. (2020). Genetic Parameters of Birth Weight, Litter Size in Crossbreeding of Boer and Indonesian Goat. Budapest International Research in Exact 
Sciences (BirEx) Journal Volume 2, No 3, Page: 273-279. www.bircujournal.com/index.php/birex

Farrokhi E, Shafei M N, Khajavirad A, Hosseini M, Bideskan A R E. (2017). Role of the Nitrergic System of the Cuneiform Nucleus in Cardiovascular Responses in UrethaneAnesthetized Male Rats. Iranian Journal of Medical Sciences.

Gargiulo G, Capodanno D, Longo G, Capranzano P,Tamburino C.(2014). Updates on NSAIDs in patients with and without coronary artery disease: pitfalls, interactions and cardiovascular outcomes. Expert review of cardiovascular therapy.

Guzman R E, Evans M G, Bove S, Morenko B, Kilgore, K.(2003). Mono-iodoacetateinduced histologic changes in subchondral bone and articular cartilage of rat femorotibial joints: an animal model of osteoarthritis. Toxicologic Pathology : 619-624.

Hosseini S E, Hamzavi S, Aghababa H.(2015). The effects of alcoholic extract of red poppy (Papaver rhoeas) on anxiety induced by elevated plus maze and the plasma corticosterone levels in adult male wistar rats .

Huston J M, Tracey K J. (2011). The pulse of inflammation: heart rate variability, the cholinergic anti-inflammatory pathway and implications for therapy. Journal of internal medicine.

Jennings A, Welch A A, Fairweather-Tait S J, Kay C, Minihane A M, Chowienczyk, P, et al. (2012). Higher anthocyanin intake is associated with lower arterial stiffness and central blood pressure in women. The American journal of clinical nutrition .

Karimian P, Kavoosi G, Amirghofran. Z.(2013). Anti-inflammatory effect of Mentha longifolia in lipopolysaccharide-stimulated macrophages: reduction of nitric oxide production through inhibition of inducible nitric oxide synthase, $J$ Immunotoxicol :393

Kent K, Charlton K E, Jenner A, \& Roodenrys S. (2016). Acute reduction in blood pressure following consumption of anthocyanin-rich cherry juice may be dose-interval dependant: a pilot cross-over study. International journal of food sciences and nutrition: 47-52.

Marcocci L., Maguire J J, Droylefaix M T, and Packer L. (1994). Nitric oxide scavengiing properties of Ginkgo biloba extract EGB 761. Bioechm. Biophys. Res. Commun: 748-75.

Osanloo N, Najafi-Abedi A, Jafari F, Javid F, Pirpiran M, Jafari M R M, et al. (2016). Papaver Rhoeas L. Hydroalcoholic Extract Exacerbates Forced Swimming TestInduced Depression in Mice. Basic and clinical neuroscience.

Perrinjaquet-Moccetti T, Busjahn A, Schmidlin C, Schmidt A, Bradl B, aydoganfood.(2008). "Supplementation with an olive (Olea europaea L.) leaf extract reduces blood pressure in borderline hypertensive monozygotic twins." Phytotherapy Research .

Qiang Xu,A,B,C,D,E,F Zuo-fu Zhang,B,E and Wei-xue SunA.(2017). Effect of Naringin on Monosodium Iodoacetate-Induced Osteoarthritis Pain in Rats. Med Sci Monit. : 3746-3751.

Reddy M K, Schultz H D, Zheng H, Patel K P. (2007). Altered nitric oxide mechanism within the paraventricular nucleus contributes to the augmented carotid body chemoreflex in heart failure. American Journal of Physiology-Heart and Circulatory Physiology : 149157

Sahraei H, Faghih-Monzavi Z, Fatemi S M, Pashaei-Rad S, Salimi S H, et al.(2006). Effects of Papaver rhoeas extract on the acquisition and expression of morphine induced behavioral sensitization in mice. Phytotherapy Research.

Wang H, Bai J, He B, Hu X, \& Liu D. (2016). Osteoarthritis and the risk of cardiovascular disease: a meta-analysis of observational studies. Scientific reports. 
Wang Z, Martorell, B C, Wälchli T, Vogel O, Fischer J, Born W, Vogel J.(2015). Calcitonin gene-related peptide (CGRP) receptors are important to maintain cerebrovascular reactivity in chronic hypertension. PloS one 123.

Zigta, Binyam. ( 2019). Thermal Radiation, Chemical Reaction and Viscous Dissipation Effects on Unsteady MHD Flow of Viscoelastic Fluid Embedded in a Porous Medium. Budapest International Research in Exact Sciences (BirEx) Journal Volume 1, No 3, July 2019, Page: 35-57 www.bircu-journal.com/index.php/birex 